\title{
Usefulness of transesophageal echocardiography before cardioversion in atrial arrhythmias
}

\author{
Katarzyna Kosmalska ${ }^{1}$, Małgorzata Rzyman ${ }^{1}$, Paweł Miękus ${ }^{1}$, \\ Natasza Gilis-Malinowska ${ }^{2}$, Radosław Nowak ${ }^{2}$, Marcin Fijałkowski ${ }^{2}$ \\ ${ }^{1}$ St. Vincent Hospital in Gdynia, Poland \\ ${ }^{2} 1^{\text {st }}$ Department of Cardiology, Faculty of Medicine, Medical University of Gdańsk, Poland
}

\begin{abstract}
Background: Although many thromboembolism risk factors are well defined, formation of thrombus or dense spontaneous contrast (sludge) in the left atrium remains enigmatic and confounding. Exclusion of the thrombus is extremely important with respect to planned reversal of sinus rhythm. Data regarding the routine transesophagal echocardiography (TEE) before cardioversion are inconclusive. The authors focused on analyzing the usefulness of TEE before cardioversion by assessment of factors influencing the risk of thrombus and/or dense spontaneous echo contrast with the intention of extending indications for TEE in the group with a high risk of thrombus or to forgo TEE in the low risk group.

Methods: Two hundred sixty-nine consecutive patients with persistent ( $>48 \mathrm{~h}$ ) atrial fibrillation or atrial flutter, in whom a direct current cardioversion was planned, were undergoing TEE for the detection of the left atrial thrombus or dense spontaneous echo contrast. Additional clinical and echocardiographic data were collected. The relationship between both thrombus and dense spontaneous echo contrast and covariates was analyzed with the use of binary logistic regression.

Results: Left atrium (LA) appendage (LAA) thrombus and/or sludge were detected in 79 (29\%) patients. Signs of dementia in mini-mental state examination (hazard ratio [HR]: 1.16; $p=0.005$ ), low velocities in LAA (HR: 3.38; $p=0.032)$; presence of spontaneous echo contrast in LA (HR: 3.38; $p=0,003$ ) consecutive episode of $A F$ (HR: 2.27; $p=0,046)$; longer duration of atrial fibrillation (HR: 1.009; $p=0.022)$; were significant predictors of thrombus and/or dense spontaneous echo contrast. None of the patients with a $C H A_{2} D S_{2} V A S c$ score $\leq 1$ had thrombus or sludge in the LAA. Among patients with a $C H A_{2} D S_{2} V A S c$ score $>1$, the prevalence of thrombus or sludge in LAA was independent of the $\mathrm{CHA}_{2} D \mathrm{~S}_{2} V A S c$ score value.

Conclusions: Amongst many factors, including an established as risk for thromboembolism only a few of them increased the risk for the presence of thrombus in LAA: low velocities in LAA, presence of spontaneous echo contrast, longer duration of arrhythmia, consecutive (not first) arrhythmia episode and signs of dementia from a mini-mental state examination questionnaire. It was believed that there could be a need for an extension of indications of TEE in vast majority of the patients with atrial arrhythmias, due most often to an unpredictable occurrence of thrombus and potentially disastrous thromboembolism. The only exception could have been the group of the patients with a $\mathrm{CHA}_{2} D \mathrm{~S}_{2} V A S c$ score $\leq 1$. (Cardiol J 2021; 28, 1: 101-109)
\end{abstract}

Key words: left atrial appendage thrombus, sludge, atrial fibrillation, atrial flutter, cardioversion, transesophagal echocardiography

Address for correspondence: Dr. Katarzyna Kosmalska, St. Vincent Hospital in Gdynia, ul. Wójta Radtkego 1, 81-348 Gdynia, Poland, e-mail: katarzyn5@wp.pl

Received: 24.01.2019 Accepted: 28.05.2019

This article is available in open access under Creative Common Attribution-Non-Commercial-No Derivatives 4.0 International (CC BY-NC-ND 4.0) license, allowing to download articles and share them with others as long as they credit the authors and the publisher, but without permission to change them in any way or use them commercially. 


\section{Introduction}

Cerebral stroke and other thromboembolic events caused by thrombus with the source in the left atrial appendage (LAA) in patients with atrial fibrillation (AF) and atrial flutter (AFl) might be the most serious complications after cardioversion. In subjects with AF, the thrombus in LAA has been recognized as a robust independent risk factor for stroke [1-3] and stands as an absolute contraindication to cardioversion. The presence of dense spontaneous echo contrast, commonly called sludge, has also been proved to be associated with high embolic risk $[4,5]$ and all-cause mortality [4]. For this reason, thrombus and sludge were recognized as equally dangerous.

An established way to prevent severe outcomes of cardioversion is the administration of anticoagulants for at least 3 weeks prior to the procedure [6-10].

Nevertheless, there are many patients diagnosed with presence of thrombus or sludge in the LAA despite proper anticoagulation [11, 12]. Transesophageal echocardiography (TEE) has been stated as an imaging technique for exclusion or confirmation thrombus and/or dense spontaneous echo contrast in the LAA $[1,2,13,14]$. In the group of patients planned for cardioversion it was recommended as a guide, especially in inadequately anticoagulated patients $[1,2,9,10]$. An unstable state of patients with inappropriate anticoagulation is also a stated indication for TEE before cardioversion in $\mathrm{AF}$ or $\mathrm{AFl}[8,15]$. Except for the above-mentioned clinical conditions, guidelines do not commit the present operators to perform TEE routinely before cardioversion, the decision for this is usually made on the assumption that the expected risk of thromboembolic complications was higher. Therefore, an unresolved issue still remains in question: to do, or not to do TEE routinely before cardioversion?

\section{Methods}

Two hundred sixty-nine consecutive patients from two medical centers (St. Vincent Hospital in Gdynia, Poland and First Department of Cardiology, Medical University of Gdansk, Poland) were prospectively enrolled from January 2016 to June 2017. In this group of patients direct current cardioversion was planned due to persistent AF or AFl. Exclusion criteria for the study were: arrhythmia shorter than $48 \mathrm{~h}$, contraindications to TEE and lack of consent. All patients included underwent
TEE and transthoracic echocardiography (TTE). Ultrasound scanners (GE, Vivid S70, Horten, Norway) equipped with a $1.5-4.6 \mathrm{MHz}$ transducer and a 3-8 MHz omniplane phase probe were used. The detailed questionnaire regarding state of health was also performed and laboratory blood samples were collected at the day of TEE. The Bioethics Committee of Medical University of Gdansk approved the study.

In cases which confirm both LAA thrombus and sludge, a decision against reversal of sinus rhythm are stated. Further procedures for these patients were made individually, depending on the clinical state of the patient and previous treatment.

Clinical, demographic, echocardiographic and social data were collected: sex, age, body mass index (BMI), $\mathrm{CHA}_{2} \mathrm{DS}_{2} \mathrm{VASc}$ score, co-morbidities, mini-mental state examination (MMSE) questionnaire, information regarding type and durance of anticoagulation, data of arrhythmia episode, medical history including smoking, healthcare quality, level of activity and self-reliance; laboratory tests including hematology, creatinine, international normalized ratio (INR), activated partial thromboplastin time (aPTT), TTE with automated 2-dimensional measurements of left ventricular ejection fraction (LVEF), presence or absence of increased filling pressure according the recommendation of European Association of Cardiovascular Imaging: $\mathrm{E} / \mathrm{e}^{\prime}>11$, mitral deceleration time $<150 \mathrm{~ms}$, isovolumetric relaxation time $<65 \mathrm{~ms}$, tricuspid regurgitation with $V \max >2.8 \mathrm{~m} / \mathrm{s}$, left atrial size measurements. In the TEE there was precise scanning of LAA at angles: 30/60/90/120 degrees and transgastric 2 -chamber 90 degrees with careful adjustment of gain and frequency in search of thrombus and dense spontaneous echo contrast (sludge) [16]. The LAA early diastolic emptying velocity was also measured. Sludge was defined, as already described in the literature, as an intracavitary echodensity with viscid gelatinous qualities giving the impression of impending precipitation but without a discrete organized mass [17]. There were also other TEE assessments: significant valvular pathology, presence of any spontaneous echo contrast (recognized as dynamic, swirling, smokelike echoes), analysis of LAA velocities and aortic plaque $[3,18]$. Both TEE and TTE were performed and analyzed by two certified echocardiographers (K.K. and M.F.).

\section{Statistical analysis}

Univariate analysis revealed differences between groups of patients with or with- 
out thrombus or/and dense spontaneous echo contrast in LAA and enabled for identification of appropriate covariates for inclusion in a binary logistic regression model. Continuous variables like $\mathrm{CHA}_{2} \mathrm{DS}_{2} \mathrm{VASc}$ and MMSE questionnaire results or duration of arrhythmia were analyzed for normality and compared using the Student $t$ test. Evaluation of the categorical variables was performed using the $\chi^{2}$ test. Pearson correlation coefficients were used to reveal correlations.

A priori alfa level was 0.05 and values resulting in $\mathrm{p}<0.05$ were statistically significant.

A multivariate logistic regression analysis was performed (with the backward likelihood ratio method and $\mathrm{p}$ for stepwise removal $>0.10$ ). A $p$ value of less than 0.05 was considered significant. Computations were performed using the Statistica version 13.1.

On the basis of results of the univariate analysis, the following variables were entered into the multivariate model: arrhythmia duration, first vs. consecutive episode, left atrium enlargement, spontaneous echo contrast, LAA velocities, non-vitamin $\mathrm{K}$ oral anticoagulants (NOACs) therapy, anticoagulation interruption, MMSE scoring, symptoms of heart failure, mitral stenosis, $\mathrm{CHA}_{2} \mathrm{DS}_{2}$ VASc scoring.

\section{Results}

The clinical and echocardiographic characteristics of patients with and without LAA thrombi/ /sludge are shown in Table 1. Patients with LAA thrombi were more often experienced in $\mathrm{AF} / \mathrm{AFl}$ (not first episode), had longer duration of arrhythmia, larger left atrium, presence of spontaneous echo contrast, lower LAA early diastolic emptying velocity, increased left ventricle filling pressures, were treated less often with non-NOACs but more often with vitamin-K antagonists (VKA), had declared inappropriate anticoagulation. Analyzing the MMSE score, they more often had a result typical of dementia, more often had symptoms of heart failure and higher scores in $\mathrm{CHA}_{2} \mathrm{DS}_{2} \mathrm{VASc}$ than those without LAA thrombi.

Thrombus and/or sludge resulting in withdrawal from cardioversion was diagnosed in 79 of 269 (29\%) patients (Fig. 1).

243 patients of the whole study group (90\%) were treated with anticoagulant. The risk of the LAA thrombus and/or dense spontaneous echo contrast in patients treated with VKA (with good therapeutic-time-ratio) was higher: $37 \%$ patients on VKA therapy had had thrombus vs. $25 \%$ in the group of patients treated with other anticoagulants; hazard ratio [HR]: 1.62. NOAC therapy in a corresponding analysis was superior to other forms of treatment (HR: 0.52), but the result was not confirmed in multivariate analysis. $\mathrm{CHA}_{2} \mathrm{DS}_{2} \mathrm{VASc}$ was significantly higher in the group of patients with thrombus and/or dense spontaneous echo contrast (mean 5 vs. 4 ) in univariate analysis but surprisingly in multivariate analysis, this factor was not significant. Of note, none of the 16 patients with $\mathrm{CHA}_{2} \mathrm{DS}_{2}$ VASc 0 or 1 had thrombus or sludge in LAA (Fig. 2).

Another startling finding was that thrombus occurred less often in a group of untreated patients or patients treated for shorter than 3 weeks. Thrombus or/and dense spontaneous echo contrast was diagnosed in 8 (14\%) patients from the group of untreated/short-term treated patients vs. 50 (26\%) among patients treated adequately but the difference was not clinically significant in both uni- and multivariate analysis.

Patients with thrombus and/or dense spontaneous echo contrast were older but the difference was not significant (median 76 vs. $73 ; \mathrm{p}=0.383$ ). In women, the presence of thrombus and/or dense spontaneous echo contrast was also more frequent (53\% patients with thrombus were female vs. $43 \%$ patients without thrombus were female), but the difference did not approach statistical significance $(\mathrm{p}=0.134)$.

Obesity was equally often in both groups of the patients with persistent $\mathrm{AF}$ (37\% vs. $36 \%$; $\mathrm{p}=0.918$ ).

No individual points of the $\mathrm{CHA}_{2} \mathrm{DS}_{2}$ VASc score revealed statistical difference: diabetes and hypertension, previous stroke or thromboembolism, vascular disease and congestive heart failure were not correlated with higher incidence of thrombus and/or dense spontaneous echo contrast.

Laboratory parameters analyzed (creatinine, hematocrit, platelets, INR, aPTT), were not correlated with higher or lower thrombus risk and/or dense spontaneous echo contrast.

In the group of echocardiographic parameters presence of moderate or severe mitral stenosis were correlated significantly (3.8\% in group with thrombus vs. $0.53 \%$ in group without thrombus; $\mathrm{p}=0.043$ ) but the result was not confirmed in multivariate analysis. Similarly, increased left ventricle filling pressures in univariate analysis correlated with higher risk of thrombus (61\% in the group of thrombus vs. $44 \%$ in group without thrombus; $p=0.018$ ), but the factor did not turn out to be an independent risk factor in binary regression. None 
Table 1. Characteristics of patients with and without left atrial appendage thrombi.

\begin{tabular}{|c|c|c|c|}
\hline & Thrombus or sludge $(+)$ & Thrombus or sludge (-) & $\mathbf{P}$ \\
\hline \multicolumn{4}{|l|}{ Clinical } \\
\hline Age & $75.76 \pm 8.26$ & $73.01 \pm 10.19$ & 0.383 \\
\hline Female sex & $42(53.16)$ & $82(43.16)$ & 0.134 \\
\hline $\mathrm{CHA}_{2} \mathrm{DS}_{2} \mathrm{VASc}$ & $5.00(4.00-6.00)$ & $4.00(3.00-5.00)$ & 0.071 \\
\hline $\mathrm{CHA}_{2} \mathrm{DS}_{2} \mathrm{VASc}>3$ & $61(77.22)$ & $138(72.63)$ & 0.376 \\
\hline First episode of AF/AFI & $24(30.38)$ & $92(48.42)$ & 0.013 \\
\hline $\mathrm{AFI}$ & $12(15.19)$ & $41(21.58)$ & 0.311 \\
\hline Arrhythmia episode duration in weeks & $52.75 \pm 106.90$ & $22.53 \pm 40.99$ & 0.012 \\
\hline BMI $\left[\mathrm{kg} / \mathrm{m}^{2}\right]$ & $28.97 \pm 5.30$ & $29.11 \pm 4.94$ & 0.840 \\
\hline Overweight & $33(41.77)$ & $79(41.58)$ & 0.939 \\
\hline Obesity & $29(36.71)$ & $69(36.32)$ & 0.918 \\
\hline Arterial hypertension & $64(81.01)$ & $147(77.37)$ & 0.435 \\
\hline Diabetes & $35(44.30)$ & $68(35.79)$ & 0.175 \\
\hline Previous stroke/TIA & $17(21.52)$ & $42(22.11)$ & 0.939 \\
\hline Vascular disease & $51(64.56)$ & $100(52.63)$ & 0.061 \\
\hline Congestive heart failure & $40(50.63)$ & $72(37.89)$ & 0.051 \\
\hline Active cancer & $2(2.53)$ & $7(3.68)$ & 1.000 \\
\hline Cancer in medical history & $6(7.59)$ & $16(8.42)$ & 1.00 \\
\hline Smoking & $5(6.33)$ & $7(3.68)$ & 0.520 \\
\hline Active inflammation & $6(7.59)$ & $14(7.37)$ & 1.000 \\
\hline Infection in last 3 months & $16(20.25)$ & 33 (17.37) & 0.729 \\
\hline Surgery in last 3 months & $4(5.06)$ & $12(6.32)$ & 0.783 \\
\hline \multicolumn{4}{|l|}{ Echocardiography } \\
\hline LVEF & $43.17 \pm 12.73$ & $46.24 \pm 11.72$ & 0.073 \\
\hline LA surface & $30.02 \pm 10.22$ & $27.05 \pm 5.22$ & 0.033 \\
\hline Presence of spontaneous echo contrast & $58(73.42)$ & $62(32.63)$ & $<0.001$ \\
\hline Low LAA velocities & $70(88.61)$ & $113(59.47)$ & 0.024 \\
\hline Aortic stenosis moderate-to-severe & $4(5.06)$ & $13(6.84)$ & 0.785 \\
\hline Aortic regurgitation moderate-to-severe & $2(2.53)$ & $6(3.16)$ & 1.000 \\
\hline Mitral stenosis moderate-to-severe & $3(3.80)$ & $1(0.53)$ & 0.077 \\
\hline Mitral regurgitation moderate-to-severe & $19(24.05)$ & $50(26.32)$ & 0.761 \\
\hline Aortic prosthesis & $4(5.06)$ & $8(4.21)$ & 0.752 \\
\hline Mitral prosthesis & $4(5.06)$ & $5(2.63)$ & 0.456 \\
\hline \multicolumn{4}{|l|}{ Laboratory } \\
\hline Creatinine $[\mathrm{mg} / \mathrm{dL}]$ & $0.99 \pm 0.38$ & $1.01 \pm 0.41$ & 0.479 \\
\hline Hematocrit [\%] & $40.49 \pm 4.57$ & $40.63 \pm 4.68$ & 0.931 \\
\hline Platelets [G/L] & $214.03 \pm 55.20$ & $220.07 \pm 82.79$ & 0.965 \\
\hline INR & $1.88 \pm 0.88$ & $1.73 \pm 0.72$ & 0.229 \\
\hline aPTT ratio & $1.35 \pm 0.39$ & $1.30 \pm 0.33$ & 0.617 \\
\hline \multicolumn{4}{|l|}{ Anticoagulation } \\
\hline Proper anticoagulation & 75 (94.94) & $168(88.42)$ & 0.061 \\
\hline Anticoagulation duration in weeks & $108.96 \pm 199.69$ & $123.05 \pm 235.11$ & 0.536 \\
\hline Anticoagulation $>4$ weeks & $67(84.81)$ & $159(83.68)$ & 0.819 \\
\hline NOAC & $38(48.10)$ & $122(64.21)$ & 0.014 \\
\hline VKA with TTR > 85\% & $29(36.71)$ & $43(22.63)$ & 0.018 \\
\hline $\begin{array}{l}\text { No anticoagulation or shorter than } 3 \text { weeks } \\
\text { or warfarin with TTR }<80 \% \text { or LMWH } \\
\text { in prophylactic dose }\end{array}$ & $8(14.04)$ & $20(12.35)$ & 0.818 \\
\hline
\end{tabular}


Table 1 (cont.). Characteristics of patients with and without left atrial appendage thrombi.

\begin{tabular}{lccc}
\hline & Thrombus or sludge (+) & Thrombus or sludge (-) & P \\
\hline Anticoagulation interruption in last 3 months & $12(15.19)$ & $11(5.79)$ & 0.028 \\
Cardiologist-controlled anticoagulation & $55 / 59(93.22)$ & $126 / 134(94.02)$ & 0.830 \\
Mini-mental state examination (MMSE) & & & \\
MMSE score & $24.67 \pm 4.51$ & $26.62 \pm 3.38$ & 0.001 \\
Mild impairment of cognitive function & $16(20.25)$ & $30(15.79)$ & 0.378 \\
Dementia & $7(8.86)$ & $2(1.05)$ & 0.003 \\
\hline
\end{tabular}

Data are shown as mean \pm standard deviation and the number of patients (percentage). AF — atrial fibrillation; atrial flutter; LA — left atrium; LAA — left atrium appendage; aPTT — activated partial thromboplastin time; BMI — body mass index; INR — international normalized ratio; LVEF — left ventricular ejection fraction; LMWH - low molecular weight heparin; NOACs — non-vitamin K oral anticoagulant; TIA — transient ischemic attack; TTR — therapeutic time ratio; VKA — vitamin $\mathrm{K}$ antagonists

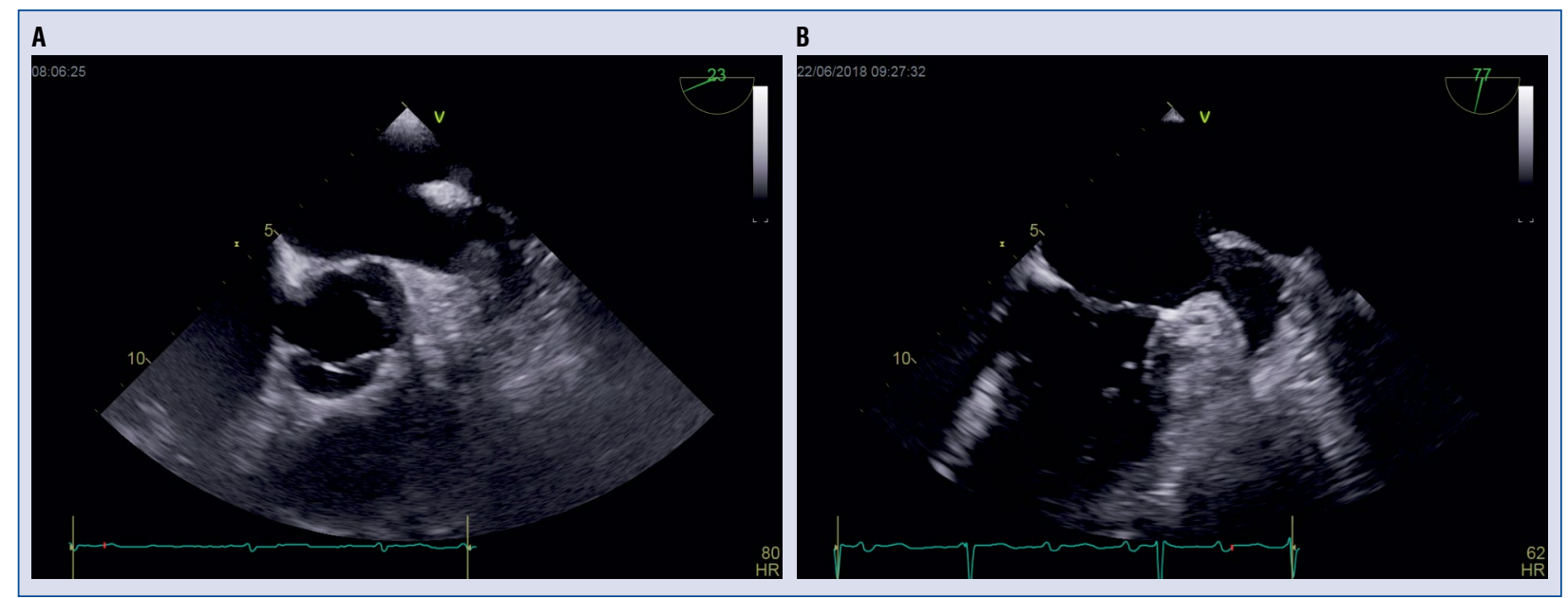

Figure 1. Examples of the left atrium appendage thrombi (A) and LAA sludge (B).

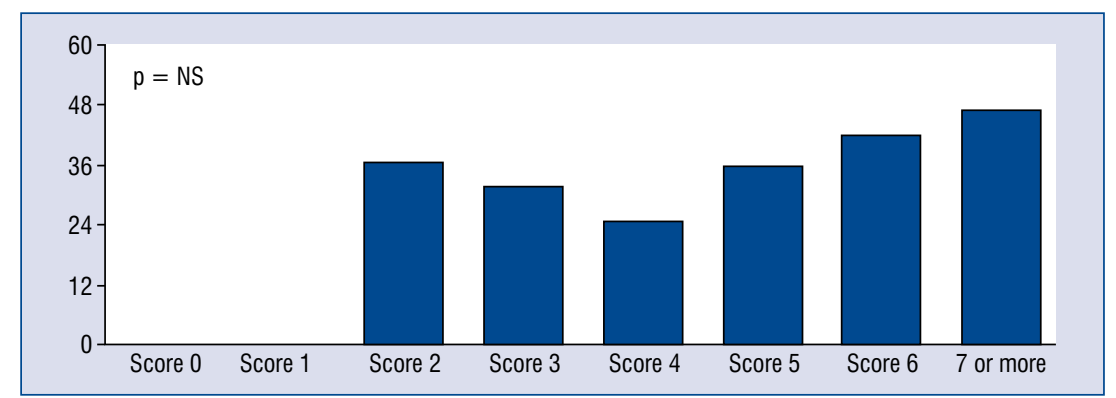

Figure 2. Percentage of patients with left atrium appendage thrombus/sludge by $\mathrm{CHA}_{2} \mathrm{DS}_{2} \mathrm{VASc}$ score.

of the other echocardiographic factors, including LVEF, significant mitral regurgitation and LAA enlargement were correlated with higher or lower risk of LAA thrombus.

Other clinical features i.e. cancer, smoking, inflammation, recent surgery, kind of arrhythmia (AF vs. $\mathrm{AFl}$ ) were not correlated with higher risk of thrombus and/or sludge.
Multivariate analysis revealed only 5 of 53 parameters analyzed as independent risk factors for thrombus/dense spontaneous echo contrast: low LAA early diastolic emptying velocities $(\mathrm{p}=0.032$; HR: 3.38; 95\% confidence interval [CI] 1.11-10.33), presence of spontaneous echo contrast $(\mathrm{p}=0.003$; HR: 3.38; 95\% CI 1.49-7.67), sequent atrial arrhythmia episode ( $\mathrm{p}=0.046$; HR: 0.44; 95\% CI 0.19-0.99), 
Table 2. Results of the multivariable analysis: independent predictors of left atrial thrombi.

\begin{tabular}{lcccc}
\hline & Univariate logistic regression & Multivariate logistic regression \\
\cline { 2 - 5 } & $\mathbf{p}$ & $\mathbf{p}$ & $\mathbf{H R}$ & $95 \% \mathrm{Cl}$ \\
\hline $\mathrm{CHA}_{2} \mathrm{DS}_{2}$ VASc & 0.049 & 0.988 & 1.002 & $0.74-1.36$ \\
Vascular disease & 0.061 & 0.646 & 1.213 & $0.53-2.76$ \\
Mitral stenosis & 0.043 & 0.999 & 2.65 & $1.54-4.09$ \\
Spontaneous echo contrast & $<0.001$ & 0.003 & 3.38 & $1.49-7.67$ \\
Low LAA velocities & $<0.001$ & 0.032 & 3.38 & $1.11-10.33$ \\
Increased filling pressure & 0.018 & 0.669 & 1.19 & $0.54-2.63$ \\
Congestive heart failure & 0.051 & 0.432 & 1.39 & $0.61-3.15$ \\
Dementia in MMSE & $<0.001$ & 0.005 & 0.86 & $0.78-0.96$ \\
NOAC & 0.014 & 0.381 & 0.69 & $0.31-1.58$ \\
Anticoagulation interruption & 0.013 & 0.242 & 2.13 & $0.60-7.55$ \\
First arrhythmia episode & 0.030 & 0.046 & 0.44 & $0.19-0.99$ \\
Arrhythmia episode duration & 0.002 & 0.022 & 1.009 & $1.01-1.02$ \\
\hline
\end{tabular}

$\mathrm{Cl}$ - confidence interval; HR - hazard ratio; LAA — left atrium appendage; MMSE - mini-mental state examination; NOAC - non-vitamin $\mathrm{K}$ oral anticoagulant

low result in MMSE ( $\mathrm{p}=0.005$; HR: $0.86 ; 95 \%$ CI 0.78-0.96) and longer duration of arrhythmia ( $\mathrm{p}=0.022$; HR: 1.009; 95\% CI 1.01-1.02) (Table 2).

\section{Discussion}

First of the important findings of the present study is high prevalence of thrombus or sludge formations in patients with $\mathrm{AF}$ and $\mathrm{AFl}$, diagnosed by TEE (29\%). Second valuable and interesting finding is that none of the patients with $\mathrm{CHA}_{2} \mathrm{DS}_{2}$ VASc score $\leq 1$ had thrombus or sludge in LAA but when patients $\mathrm{CHA}_{2} \mathrm{DS}_{2} \mathrm{VASc}$ score $\leq 1$ are excluded, thrombus occurrence do not correlate with of $\mathrm{CHA}_{2} \mathrm{DS}_{2}$ VASc scores. Third, unique finding is that we have discovered only one independent risk factor for thrombus formation before TEE performance; cognitive impairment diagnosed in MMSE. There are two other independent risk factors; low early diastolic emptying velocities in LAA and the presence of spontaneous echo contrast, but they were diagnosed during TEE, therefore cannot reveal whether to do or not to do TEE before cardioversion.

It was decided to put into the analysis both cases of thrombus and dense spontaneous echo contrast (sludge). Differentiation between those two entities is difficult especially before a decision of reversal of sinus rhythm [14]. It has been demonstrated that the presence of sludge is strongly associated with thrombus, embolic events and poor prognosis $[4,5]$. In retrospective analysis of Lowe et al. [3] the presence of sludge correlated with similar risk of death but higher risk of thromboembolism than thrombus appearance.

The general incidence of thrombus/sludge in the present study was high. This fact might have been caused by prospective nature of the study, especially by a further decision for cardioversion which compelled recognition in uncertain cases as LAA thrombus. Nonetheless, in several similar studies the incidence is equal or even higher $[3,19,20]$.

In this prospective study of 269 consecutive patients with $\mathrm{AF}$ and $\mathrm{AFl}$ undergoing TEE, before attempting cardioversion, many clinical, echocardiographic and social factors were taken into account which might have influenced thrombus formation. Among the multiple factors only low LAA early diastolic emptying velocities, presence of spontaneous echo contrast, sequent episode of $\mathrm{AF} / \mathrm{AFl}$, dementia in MMSE, longer episodes of arrhythmia were independent risk factors for thrombus formation. Converse to other studies, no significant difference was noted in age, sex, LVEF, renal function, lower or higher $\mathrm{CHA}_{2} \mathrm{DS}_{2} \mathrm{VASc}$ score [21-24], however, in the group with a risk score 0 or 1 no thrombi or dense spontaneous echo contrast in LAA was diagnosed. In the group scoring higher (two or more) there was no statistical difference between the number of points in $\mathrm{CHA}_{2} \mathrm{DS}_{2} \mathrm{VASc}$ score and risk of thrombus.

The present results may underlie creating hypotheses with potential implications for clinical decision-making. Regarding contemporary recom- 
mendations, in cases of anticoagulation 3 weeks prior cardioversion can be performed without the need of any other diagnostic tests. Nevertheless, the thrombus or sludge was diagnosed in $25 \%$ of patients with declared proper anticoagulation. This fact might be a source for beginning a discussion over extending indications for TEE before cardioversion, similar to the current discussion over necessity of TEE before AF ablation - most ablation centers perform TEE routinely despite the general low risk of thrombus/slugde [25, 26]. This procedure could be supported by important clinical outcomes although the evidence given in guiding this decision is limited [27]. The extension of TEE indications is additionally favored if the results of the ACUTE trial take into account, especially lower risk of hemorrhage and higher success rate in sinus rhythm reversal in TEE guided patients [7]. Despite the fact, that there are reports on the usefulness of other echocardiographic techniques for the prediction of thrombus in LAA, TEE before cardioversion still remains the gold standard. Kupczynska et al. [28] have demonstrated the value of speckle-tracking analysis of the LA wall to identify patients with higher risk of thrombus. Additionally, both LVEF and global longitudinal turned out to be an independent risk factor for thrombus and provided additional diagnostic value for discriminating between patients with and without left atrial thrombus [29].

One of the most relevant and clinically important findings of the study is the relationship between cognitive dysfunction and thrombus (Figs. 3, 4). Cognitive disorders are very common in patients with chronic AF and low anticoagulation compliance was observed in this group [19]. Those patients should be advised that they would be subjected to TEE before cardioversion independently of a declared period of treatment. According to available research this is the first study that suggests cognitive disorders as an independent LAA thrombus or sludge risk factor.

The $\mathrm{CHA}_{2} \mathrm{DS}_{2}$ VASc score has clinical prediction rules for estimating the risk of stroke in patients with non-rheumatic $\mathrm{AF}$ associated with thromboembolic stroke. Such a score is used to determine whether or not treatment is required with anticoagulation therapy or antiplatelet therapy and gives a better stratification of low-risk patients. Indeed, in the present study not a single case of thrombus occurred in the group with very low thromboembolic risk $\left(\mathrm{CHA}_{2} \mathrm{DS}_{2} \mathrm{VASc} \leq 1\right)$. The fact that reflects the accuracy of $\mathrm{CHA}_{2} \mathrm{DS}_{2}$ VASc score may help to identify patients in forgoing

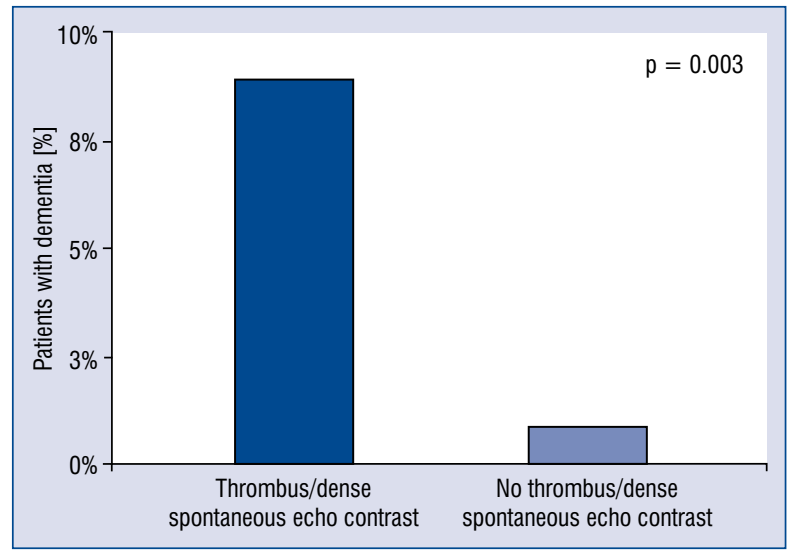

Figure 3. Percentage of patients with dementia and the presence of left atrium appendage thrombus/sludge.

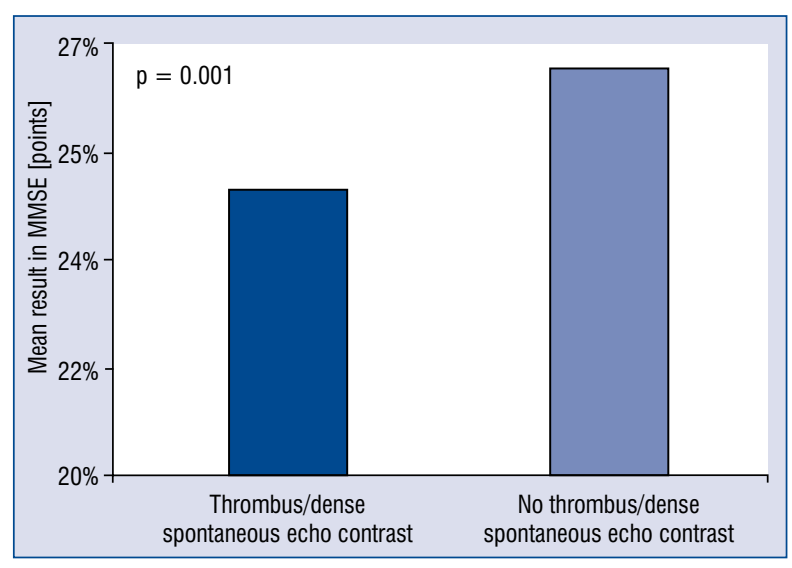

Figure 4. Results of mini-mental state examination (MMSE) questionnaire test and the presence of left atrium appendage thrombus/sludge.

TEE before cardioversion, but these results should be confirmed in larger studies [30]. Additionally, although $\mathrm{CHA}_{2} \mathrm{DS}_{2}$ VASc score correlates directly with annual stroke risk, among patients in this study with $\mathrm{CHA}_{2} \mathrm{DS}_{2} \mathrm{VASc}>1$ the prevalence of thrombus or sludge in LAA was independent of $\mathrm{CHA}_{2} \mathrm{DS}_{2}$ VASc score values that could suggest additional risk factors of stroke in patients with a higher score like atherosclerosis and arterial hypertension. Usefulness of dichotomous scoring of $\mathrm{CHA}_{2} \mathrm{DS}_{2}$ VASc values $(\leq 1$ and $>1$ ) could simplify clinical every day routine but requires further evaluation.

\section{Limitations of the study}

The most important limitation is the uncertain cases that were recognized as suspected thrombus 
and were included in the analysis. In both of the documented centers there was a possibility to perform differentiation with the use of echocardiographic contrast or computed tomography but the decision reached was not to use any of those methods to adjust to clinical conditions in all wards performing direct current cardioversion due to the high cost and lack of widespread availability for these methods.

Data regarding anticoagulation were based on questionnaires, with the exception of VKA-treated patients (INR performed once a week for 3 weeks before direct current cardioversion). Additionally, the focus was not on the important issue of whether and when TEE should be repeated to check if the thrombus has been dissolved in anticoagulant therapy.

Cost-effective analysis goes beyond this study but might be a valuable complement.

\section{Conclusions}

It is believed herein, that there could be a need for an extension of indications to TEE in a vast majority of patients with atrial fibrillation and atrial flutter.

\section{References}

1. Pepi M, Evangelista A, Nihoyannopoulos P, et al. Recommendations for echocardiography use in the diagnosis and management of cardiac sources of embolism: European Association of Echocardiography (EAE) (a registered branch of the ESC). Eur J Echocardiogr. 2010; 11(6): 461-476, doi: 10.1093/ejechocard/ jeq045, indexed in Pubmed: 20702884.

2. Saric M, Armour AC, Arnaout MS, et al. Guidelines for the Use of Echocardiography in the Evaluation of a Cardiac Source of Embolism. J Am Soc Echocardiogr. 2016; 29(1): 1-42, doi: 10.1016/j. echo.2015.09.011, indexed in Pubmed: 26765302.

3. Lowe BS, Kusunose K, Motoki H, et al. Prognostic significance of left atrial appendage "sludge" in patients with atrial fibrillation: a new transesophageal echocardiographic thromboembolic risk factor. J Am Soc Echocardiogr. 2014; 27(11): 1176-1183, doi: 10.1016/j.echo.2014.08.016, indexed in Pubmed: 25262162.

4. Fatkin D, Kelly RP, Feneley MP. Relations between left atrial appendage blood flow velocity, spontaneous echocardiographic contrast and thromboembolic risk in vivo. J Am Coll Cardiol. 1994; 23(4): 961-969, indexed in Pubmed: 8106703.

5. Bernhardt P, Schmidt H, Hammerstingl C, et al. Patients at High Risk with Atrial Fibrillation: A Prospective and Serial Follow-up During 12 Months with Transesophageal Echocardiography and Cerebral Magnetic Resonance Imaging. J Am Coll Cardiol. 2005; 45: 1807-1812, doi: 10.1016/j.echo.2005.01.028.

6. Fatkin D, Loupas T, Jacobs N, et al. Quantification of blood echogenicity: evaluation of a semiquantitative method of grading spontaneous echo contrast. Ultrasound Med Biol. 1995; 21(9): 1191-1198, indexed in Pubmed: 8849833.
7. Asher CR, Klein AL. The ACUTE trial. Transesophageal echocardiography to guide electrical cardioversion in atrial fibrillation. Assessment of Cardioversion Using Transesophageal Echocardiography. Cleve Clin J Med. 2002; 69(9): 713-718, indexed in Pubmed: 12222975.

8. Hart RG, Benavente O, McBride R, et al. Antithrombotic therapy to prevent stroke in patients with atrial fibrillation: a metaanalysis. Ann Intern Med. 1999; 131(7): 492-501, indexed in Pubmed: 10507957.

9. Kirchhof P, Benussi S, Kotecha D, et al. 2016 ESC Guidelines for the management of atrial fibrillation developed in collaboration with EACTS. Eur Heart J. 2016; 37(38): 2893-2962, doi: 10.1093/eurheartj/ehw210.

10. January CT, Wann LS, Alpert JS, et al. 2014 AHA/ACC/HRS Guideline for the Management of Patients With Atrial Fibrillation: Executive Summary A Report of the American College of Cardiology/American Heart Association Task Force on Practice Guidelines and the Heart Rhythm Society. J Am Coll Cardiol. 2014; 64: 2246-2280.

11. Diaconu N, Grosu A, Gratii C, et al. Is mini mental state examination helpful for CHA2DS2-VASc score? Eur Heart J. 2013; 34(suppl 1): 3681-3681, doi: 10.1093/eurheartj/eht309.3681.

12. Wu MS, Gabriels J, Khan M, et al. Left atrial thrombus despite continuous direct oral anticoagulant or warfarin therapy in patients with atrial fibrillation: insights into rates and timing of thrombus resolution. J Interv Card Electrophysiol. 2018; 53(2): 159-167, doi: 10.1007/s10840-018-0432-1, indexed in Pubmed: 30078133.

13. Manning WJ, Weintraub RM, Waksmonski CA, et al. Accuracy of transesophageal echocardiography for identifying left atrial thrombi. A prospective, intraoperative study. Ann Intern Med. 1995; 123(11): 817-822, indexed in Pubmed: 7486462.

14. Fatkin D, Scalia G, Jacobs N, et al. Accuracy of biplane transesophageal echocardiography in detecting left atrial thrombus. Am J Cardiol. 1996; 77(4): 321-323, indexed in Pubmed: 8607421.

15. Lip GYH, Nieuwlaat R, Pisters R, et al. Refining clinical risk stratification for predicting stroke and thromboembolism in atrial fibrillation using a novel risk factor-based approach: the euro heart survey on atrial fibrillation. Chest. 2010; 137(2): 263-272, doi: 10.1378/chest.09-1584, indexed in Pubmed: 19762550.

16. Fatkin D, Loupas T, Jacobs N, et al. Quantification of blood echogenicity: evaluation of a semiquantitative method of grading spontaneous echo contrast. Ultrasound Med Biol. 1995; 21(9): 1191-1198, indexed in Pubmed: 8849833.

17. Troughton RW, Asher CR, Klein AL. The role of echocardiography in atrial fibrillation and cardioversion. Heart. 2003; 89(12): 1447-1454, doi: 10.1136/heart.89.12.1447, indexed in Pubmed: 14617563.

18. Flachskampf FA, Badano L, Daniel WG, et al. Recommendations for transoesophageal echocardiography: update 2010. Eur J Echocardiogr. 2010; 11(7): 557-576, doi: 10.1093/ejechocard/ jeq057, indexed in Pubmed: 20688767.

19. Nishimura M. The high incidence of left atrial appendage thrombosis in patients on maintenance haemodialysis. Nephrology Dialysis Transplantation. 2003; 18(11): 2339-2347, doi: 10.1093/ ndt/gfg399.

20. Stoddard MF, Dawkins PR, Prince CR, et al. Left atrial appendage thrombus is not uncommon in patients with acute atrial fibrillation and a recent embolic event: a transesophageal echocardiographic study. J Am Coll Cardiol. 1995; 25(2): 452-459, indexed in Pubmed: 7829800. 
21. Chao TF, Tsao HM, Ambrose K, et al. Renal dysfunction and the risk of thromboembolic events in patients with atrial fibrillation after catheter ablation--the potential role beyond the $\mathrm{CHA}_{2} \mathrm{DS}_{2}$-VASc score. Heart Rhythm. 2012; 9(11): 1755-1760, doi: 10.1016/j.hrthm.2012.06.039, indexed in Pubmed: 22760084.

22. Piccini JP, Stevens SR, Chang Y, et al. Renal dysfunction as a predictor of stroke and systemic embolism in patients with nonvalvular atrial fibrilla- tion: validation of the R(2)CHADS(2) index in the ROCKET AF (Rivaroxaban Once-daily, oral, direct factor Xa inhibition Compared with vitamin $\mathrm{K}$ antagonism for prevention of stroke and Embolism Trial in Atrial Fibrillation) and ATRIA (AnTicoagulation and Risk factors In Atrial fibrillation) study cohorts. Circulation. 2013; 127: 224-232.

23. Banerjee A, Fauchier L, Vourc'h P, et al. Renal impairment and ischemic stroke risk assessment in patients with atrial fibrillation: the Loire Valley Atrial Fibrillation Project. J Am Coll Cardiol. 2013; 61(20): 2079-2087, doi: 10.1016/j.jacc.2013.02.035, indexed in Pubmed: 23524209.

24. Kornej J, Hindricks G, Kosiuk J, et al. Renal dysfunction, stroke risk scores (CHADS2, CHA2DS2-VASc, and R2CHADS2), and the risk of thromboembolic events after catheter ablation of atrial fibrillation: the Leipzig Heart Center AF Ablation Registry. Circ Arrhythm Electrophysiol. 2013; 6(5): 868-874, doi: 10.1161/ CIRCEP.113.000869, indexed in Pubmed: 24047706.

25. Puwanant S, Varr BC, Shrestha K, et al. Role of the CHADS2 score in the evaluation of thromboembolic risk in patients with atrial fibrillation undergoing transesophageal echocardiography before pulmonary vein isolation. J Am Coll Cardiol. 2009;
54(22): 2032-2039, doi: 10.1016/j.jacc.2009.07.037, indexed in Pubmed: 19926009.

26. Calvo N, Mont L, Vidal B, et al. Usefulness of transoesophageal echocardiography before circumferential pulmonary vein ablation in patients with atrial fibrillation: is it really mandatory? Europace. 2011; 13(4): 486-491, doi: 10.1093/europace/euq456, indexed in Pubmed: 21186230.

27. Calkins H, Hindriks G, Cappatto R. 2017 HRS/EHRA/ECAS/ APHRS/SOLAECE expert consensus statement on catheter and surgical ablation of atrial fibrillation: Executive summary catheter and surgical ablation of atrial fibrillation: Executive summary. J Arrhythm. 2017; 33(5): 369-409.

28. Kupczynska K, Michalski BW, Miskowiec D, et al. Association between left atrial function assessed by speckle-tracking echocardiography and the presence of left atrial appendage thrombus in patients with atrial fibrillation. Anatol J Cardiol. 2017; 18(1): 15-22, doi: 10.14744/AnatolJCardiol.2017.7613, indexed in Pubmed: 28559531.

29. Kupczynska K, Michalski BW, Miskowiec D, et al. Incremental value of left atrial mechanical dispersion over CHA DS -VASc score in predicting risk of thrombus formation. Echocardiography. 2018; 35(5): 651-660, doi: 10.1111/echo.13899, indexed in Pubmed: 29691894.

30. Wasmer K, Köbe J, Dechering D, et al. CHADS(2) and CHA(2) DS (2)-VASc score of patients with atrial fibrillation or flutter and newly detected left atrial thrombus. Clin Res Cardiol. 2013; 102(2): 139-144, doi: 10.1007/s00392-012-0507-4, indexed in Pubmed: 22983022. 